\title{
Notas sobre inclusão, surdez e a aquisição da Língua Portuguesa
}

\author{
Notes on inclusion, deafiness and Portuguese Language acquisition \\ Notas sobre inclusión, sordera y adquisición de la Lengua Portuguesa
}

\section{Resumo}

O surdo e a aquisição da língua portuguesa nos remetem a questões de origem inclusiva que há tempos buscam uma normatização quanto às relações sociais, uma vez que seus objetivos estão pautados nas políticas públicas. Com o objetivo de entender como esse processo foi e está sendo inserido, buscou-se por meio de uma pesquisa bibliográfica, fazer essa análise comparativa e evolutiva aguçando uma discussão a respeito desse assunto. Alguns autores como Sacks, Kleiman, Kojima, Segala dentre outros, nos ajudaram a evidenciar algumas temáticas. Essa análise é de tendência da práxis, ou seja, da teoria e da prática, levando a uma reavaliação de como nós, futuros professores podemos contribuir na inclusão dos surdos nas escolas e também no meio social, já que estes podem colaborar ainda mais, exercendo seu papel como cidadão.

Palavras-chave: Surdos; Inclusão; Língua portuguesa.

\begin{abstract}
The deaf and the acquisition of the Portuguese language lead us to issues of inclusive origin that for some times have been seeking a standardization of social relations, as their goals are based on public policies. In order to understand how this process was and is being inserted, it was sought, through a bibliographical research, to make this comparative and evolutionary analysis, sharpening a discussion about this subject. Some authors such as Sacks, Kleiman, Kojima, Segala among others, helped us to clarify some themes. This analysis is based on praxis, that is, theory and practice, leading to a reassessment of how we, future teachers, can contribute to the inclusion of deaf people in schools and also in the social environment, as they can still collaborate more, exercising its role as a citizen. Keywords: Deaf; Inclusion; Portuguese language.
\end{abstract}




\begin{abstract}
Resumen
Los sordos y la adquisición de la lengua portuguesa nos llevan a temas de origen inclusivo que desde hace algún tiempo buscan una estandarización de las relaciones sociales, pues sus objetivos se basan en políticas públicas. Para comprender cómo fue y se está insertando este proceso, se buscó, a través de una investigación bibliográfica, realizar este análisis comparativo y evolutivo, agudizando una discusión sobre este tema. Algunos autores como Sacks, Kleiman, Kojima, Segala entre otros, nos ayudaron a aclarar algunos temas. Este análisis se basa en la praxis, es decir, la teoría y la práctica, lo que lleva a una reevaluación de cómo nosotros, futuros profesores podemos contribuir a la inclusión de las personas sordas en las escuelas y también en el entorno social, ya que aún pueden colaborar más, ejerciendo su papel de ciudadano.
\end{abstract}

Palabras clave: Sordo; Inclusión; Lengua portuguesa.

\title{
1. Introdução
}

Infelizmente, por muito tempo acreditou-se que os surdos eram inferiores aos ouvintes no que se refere a seres humanos em termos de potencial e inteligência. Eram pessoas excluídas da sociedade, não tinham direito a herança nem podiam escolher um parceiro para casar (Santana, 2007). Atualmente os surdos, enquanto minoria linguística estão conquistando seu espaço. Depois de momentos de lutas e muitas conquistas estamos vivendo um período de acomodação que perpassa da lei para a necessidade real (Strobel, 2008). Tal realidade é composta de resistência e falta de conhecimento por parte da sociedade envolvida, pais, professores, educadores e até mesmo algumas pessoas surdas, geralmente de idade mais avançada, pois, muitas vezes não compreenderam a importância da Língua Brasileira de Sinais na educação dos surdos (Schemberg, Guarinello, \& Massi, 2012).

Como se sabe é comum que muitos surdos não têm o conhecimento da própria língua, a de sinais, isso se torna até certo ponto um entrave para o desenvolvimento da pessoa com surdez uma vez que os surdos são indivíduos que se relacionam com o mundo por meio da linguagem visual/espacial e da cultura própria. Ter uma língua em comum é importante não apenas do ponto de vista da comunicação, mas também para o desenvolvimento intelectual, afetivo, emocional da criança. O ideal é que os pais enfrentem esse desafio, aprendam LIBRAS e que as crianças aprendam a língua de sinais e também seja exposta à Língua Portuguesa escrita (Strobel, 2008).

A língua portuguesa funciona como segunda língua para a pessoa com surdez, porém ela deve ser oferecida a essas pessoas para que elas possam inserir-se na comunidade e na cultura dos ouvintes da nação a que pertencem podendo com isso participar ativamente dos processos de desenvolvimento da sociedade como um todo.

Diante do exposto é possível perceber que a pessoa com surdez necessita de uma educação em que se ofereça o ensino das línguas que oferecerá possibilidade para essas pessoas inserirem-se na cultura a que pertencem. Por isso é preciso que a escola se proponha a oferecer um ensino bilíngue. Segundo Quadros (2008 p.35):

A educação de surdos na perspectiva bilíngue toma uma forma que transcende as questões puramente linguísticas. Para além da língua de sinais e do português esta educação situa-se no contexto de garantia de acesso e permanência na escola. A escola está sendo definida pelos próprios movimentos surdos: marca fundamental da consolidação de uma educação de surdos em um país que se entende equivocadamente monolíngue. O confronto se faz necessário para que se constitua uma educação verdadeira: multilíngue e multicultural.

Assim como a língua portuguesa para o ouvinte a Libras tem o mesmo papel na vida do indivíduo surdo, pois as construções mentais utilizam a comunicação como alavanca para o desenvolvimento.

\section{A Educação e a Pessoa com Surdez}

Sabe-se que a relação educação e pessoa com surdez nunca foi adequada no que se refere ao tratamento dado ao surdo, desde a assumida pela família e sociedade até o tratamento disponibilizado para a pessoa com surdez nas instituições educacionais. Felizmente com o passar do tempo e esforços de pais e sociedade essa realidade vem mudando apesar de ainda 
haver necessidades de melhorias em aspectos diversos como postura do sistema educacional e até mesmo da família em conhecer e apropriar-se de informações que podem induzir à busca mais intensa pela formação educacional a que o aluno tem direito (Araújo et al, 2020).

A educação para pessoas com surdez só se iniciou em épocas já próximas ao século XVI. De acordo com Sacks (1990), os primeiros educadores surgiram com um interesse que não se baseava só na educação dessas pessoas, mas havia interesses medicinais, de interesses financeiros e de catequização por parte da medicina da família e da igreja católica respectivamente. A primeira se interessava por pesquisas, a segunda precisava que seus filhos primogênitos dominassem a fala para poderem ser considerados humanos e ter direito à herança e a terceira por interesses, também, em não "perder" as famílias mais abastadas, uma vez que, na época, era comum que pessoas da mesma família se juntassem matrimonialmente para fins de não dividir seus bens, logo era comum que houvesse pessoas com deficiência nessas famílias, então a igreja se preocupou, devido ao fato de os Surdos terem de se confessar e de falar os sacramentos, em criar uma forma de fazê-los mesmo através de gestos (Skilar, 2006).

Mais tarde, já no século XVII, por conta da possibilidade de ganhos financeiros, houve um grande interesse por parte de estudiosos em educação de Surdos, pois perceberam que as famílias com poder aquisitivo elevado custeavam a preços altos a educação de seus filhos para que os mesmos se habilitassem em falar e escrever. Para tanto educadores passaram a utilizar-se de alfabeto com uso das mãos para ensinar as palavras e seus significados para a pessoa com surdez. Durante o decorrer dos anos e as tentativas de educação das pessoas com surdez houve uma época em que foi proibido o método que usava os sinais como forma de comunicação do surdo, já no século XX o surdo que não se adaptasse à língua oral era considerado retardado. O que se observa com isto é que para não sair de sua zona de conforto o mundo ouvinte tenta impor que o surdo mude e se adapte à situação de ouvinte, essa pessoa é então, novamente desconsiderada em sua condição de pessoa que não ouve e que, portanto tem suas diferenças (Kleiman, 2000, 2004).

Em se tratando de educação escolar para pessoas com surdez reportamo-nos há séculos anteriores, nisso retomamos a como eram as concepções educacionais disponibilizadas ao Surdo no decorrer da história. Tais abordagens vão desde o oralismo, a comunicação total até a abordagem por meio do bilinguismo.

Segundo Damazio (2007). a educação que se baseou no oralismo, objetivava a capacitação da pessoa com surdez para a utilização da língua da comunidade ouvinte na modalidade oral, como única possibilidade linguística o uso da voz e da leitura labial, tanto na vida social, como na escola. A proposta do oralismo que não aceitava a língua de sinais das pessoas com surdez e centrava os processos educacionais na visão da reabilitação e naturalização biológica não obteve êxito. Nessa concepção o Surdo não era visto como uma pessoa diferente da ouvinte em suas necessidades educacionais, ou seja, a ele eram aplicados os mesmos "parâmetros" de ensino e aprendizagem que eram sobrepostos aos ouvintes.

A abordagem que enfoca a comunicação total, diferentemente do oralismo, trata o Surdo de forma mais abrangente, pois leva em consideração suas características e aceita o uso de diversas formas de tratar e recursos que possibilitem o acesso e a possibilidade de comunicação da pessoa com surdez (Kleiman, 2004). Segundo Damázio (2007), essa investida também foi frustrada, pois ao se deparar com os desafios cotidianos o Surdo não estava preparado, já que não fora incluído em sua formação educacional habilidades que lhe possibilitasse um desenvolvimento satisfatório, sendo assim a pessoa com surdez continuou segregada, ou seja, excluída de um contexto maior.

A educação baseada no bilinguismo surge como uma possibilidade de desenvolvimento para a pessoa com surdez, pois propende capacitar essa pessoa para o uso das duas línguas, a de sinais e a da pessoa ouvinte, tanto no contexto escolar quanto na vida secular. De acordo com Damázio (2007, p.45) "Estudos têm demonstrado que esta abordagem corresponde melhor às necessidades do aluno com surdez, em virtude de respeitar a língua natural e construir um ambiente propício para a sua aprendizagem escolar" 
De acordo com o Decreto 5.626, de 5 de dezembro de 2005, as pessoas com surdez têm direito a uma educação que garanta a sua formação, em que a Língua Brasileira de Sinais e a Língua Portuguesa, preferencialmente na modalidade escrita, constituam línguas de instrução, e que o acesso às duas línguas ocorra de forma simultânea no ambiente escolar, colaborando para o desenvolvimento de todo o processo educativo (Brasil, 2002).

Com este decreto é possível se visualizar uma inclusão de pessoas que até então se viam marginalizadas, fora de um plano de desenvolvimento pleno. Contudo, mais do que a utilização de uma língua, os alunos com surdez precisam de ambientes educacionais estimuladores, que desafiem o pensamento, a criticidade e explorem suas capacidades, em todos os sentidos (Brasil, 2002)..

Conforme Dorziat (1998), os professores precisam conhecer e usar a Língua de Sinais, entretanto, deve-se considerar que a simples adoção dessa língua não é suficiente para escolarizar o aluno com surdez. Assim, a escola comum precisa programar ações que tenham sentido para os alunos em geral e que esse sentido possa ser compartilhado com os alunos com surdez.

Nesse contexto apresenta-se mais um entrave, no que se refere à profissionalização: há falta de professores bilíngues, os currículos são inadequados e os ambientes bilíngues, quase inexistentes. Não se podem descartar também outros fatores, como: dificuldade para se formar professores com surdez num curto período de tempo; a presença de um segundo professor de Língua Portuguesa para os alunos surdos e a falta de conhecimento a respeito do bilinguismo (Nader \& Pinto, 2011).

\section{Primeira Língua: a Materna}

Mediante as representações apresentadas durante o período histórico, pode se afirmar que os surdos tem sua própria identidade, sua própria cultura. Há uma vontade de comunicação e de integração com a sociedade, por isso a busca por tentar concretizar seu desejo através do ensino da alfabetização de libras. O Surdo precisa sentir que faz parte da sociedade, quando se faz ser entendido e quando entende o que está ao seu redor, de fato ele precisa participar deste meio. Sendo assim, deve-se entender essa cultura e buscar adaptar ao contexto social. Segundo Perlin (2004, p.77):

A cultura surda é então a diferença que contém a prática social dos surdos e que comunica um significado (...) o jeito de usar sinais, o jeito de ensinar e de transmitir cultura, a nostalgia por algo que é dos surdos, o carinho para com os achados surdos do passado, o jeito de discutir a política, a pedagogia, etc.

Como toda comunidade que, obviamente tem sua cultura, um dos predicativos do surdo é que este possui sua forma de comunicação, pois é por meio dela que se dá a interação entre os indivíduos de uma comunidade e consequentemente seu desenvolvimento. Essa forma de comunicação é natural e, portanto considerada língua materna, para o Surdo essa língua é a de sinais.

Apesar de estarmos vivendo tempos em que depois de muitas batalhas superadas e que os direitos do Surdo foram finalmente reconhecidos ainda há resistência e falta de conhecimento por parte da sociedade envolvida, pais, professores, educadores e até mesmo do próprio surdo, pois não compreenderam a importância da Língua Brasileira de Sinais na educação dos surdos.

Segundo Machado (2007) a comunicação linguística acontece quando significantes imagens e sons são associados a um contexto transformados em uma mensagem que se deseja expressar.

É por meio da língua que a cultura é produzida e disseminada. Infelizmente a maioria das crianças surdas não tem o mesmo privilégio das ouvintes de ter a língua materna desde bebês. Contudo sabe-se que a surdez não limita o acesso a qualquer tipo de linguagem. 
Como no exposto, a língua materna do surdo é a língua de sinais, no Brasil LIBRAS, uma vez que é esta a língua que ele adquire espontaneamente e que ele pode dominar plenamente, pois utiliza o meio espaço-visual, que é o normalmente desenvolvido pelo indivíduo surdo (Brasil, 2002). Como toda Língua materna, a Libras é a língua que desperta a subjetividade e a capacidade de compreensão do indivíduo com surdez. Como possui estrutura e organização própria a Libras é considerada uma língua, é reconhecida também por lei. A lei que a regulamenta é a No 10.436, DE 24 DE ABRIL DE 2002, que em seu artigo primeiro diz:

Art. $1^{\circ}$ É reconhecida como meio legal de comunicação e expressão a Língua Brasileira de Sinais - Libras e outros recursos de expressão associados.

Parágrafo único. Entende-se como Língua Brasileira de Sinais - Libras a forma de comunicação e expressão, em que o sistema linguístico de natureza visual-motora, com estrutura gramatical própria, constitui um sistema linguístico de transmissão de ideias e fatos, oriundos de comunidades de pessoas surdas do Brasil.

De muitas conquistas dos surdos depois de muitas repressões destaca-se com esta lei um grande avanço, pois é através da LIBRAS, ou seja, do meio espaço visual, que o surdo interage e interpreta o mundo a sua volta e como todo ser humano, precisa dessa interação para desenvolver-se plenamente. Mesmo o Surdo que não teve acesso a Libras na infância se comunica por uma linguagem gestual essa forma de comunicação, porém é restrita e permite a pessoa de se comunicar com determinadas pessoas do seu convívio, na maior parte das vezes familiares, já em um contexto social mais amplo essa pessoa não consegue estabelecer a comunicação no sentido de se fazer compreendido e também de entender o outro num contexto social mais diversificado (Nóbrega et al, 2012).

O que notamos é que a escola de ensino regular precisa se adequar a essa nova cultura, já que hoje com o avanço histórico isso deve se fazer presente, por isso há de se englobar em todo o ensino o aprendizado de libras, universidades devem formar profissionais aptos para isso, assim como o sistema deve investir mais para essa adequação. Um dos passos importantes foi o decreto $\mathrm{n}^{\circ}$ 5.626/05 onde há uma regulamentação da Lei de Libras que define a inclusão de pessoas surdas ou com deficiências auditivas, por meio da organização de escolas e classes bilíngues, nas quais as Libras e a Língua Portuguesa sejam línguas de instrução. Outro aspecto importante foi em relação à profissão de intérprete de libras, que deu apoio à profissão a partir de 1987, para que tivesse o reconhecimento necessário e tratou das questões relativas a este exercício com mais rigor (Kajima \& Segala, 2008).

Acredita-se que o ensino da língua de sinais para o Surdo é de grande valia, pois a partir disto ele poderá participar da sociedade como todo cidadão. Para tanto é necessário que se compreenda também, que as línguas de sinais não são universais. Cada uma tem a sua própria estrutura gramatical e assim, como não temos uma língua oral única, também não temos apenas uma língua de sinais. A língua de sinais, assim como a língua oral, é a representação da cultura de um povo. Mesmo países com a mesma língua oral possuem línguas de sinais diferentes. Um exemplo é o caso de Brasil e Portugal. Por mais que esses países possuam a mesma língua oral, possuem línguas de sinais diferentes, com características próprias. O contrário acontece com os Estados Unidos e o Canadá, que possuem a mesma língua oral e a mesma língua de sinais. Segundo Kajima \& Segala (2008, p.4): A Língua de Sinais é a língua natural da comunidade surda. Esta língua, com regras morfológicas, sintáticas, semânticas e pragmáticas próprias, possibilita o desenvolvimento cognitivo da pessoa surda, favorecendo o acesso desta aos conceitos e aos conhecimentos existentes na sociedade.

\section{A Aquisição da Segunda Língua: a Portuguesa}

Como já sabemos a Língua Portuguesa, no Brasil, deve ser aplicada ao Surdo como uma segunda língua já que a sua primeira língua é a de sinais. A língua portuguesa deve ser ensinada aos alunos surdos visando o desenvolvimento da leitura e 
da escrita. Para que o aluno surdo aprenda eficazmente a segunda língua, acredita-se, que seja necessário que este faça uso de sua língua materna, no caso, a Libras. Por meio desta é possível que haja uma intermediação para a aquisição da segunda língua pelos surdos (Muncinelli, 2013).

De acordo com estudo sobre Contribuições de Fatores Sócio-Interacionistas na Escrita de Surdos realizados por Fantinel e Rampelotto o aluno surdo que possui a Libras quando exposto ao processo de aquisição da Língua Portuguesa, em sua modalidade escrita desenvolverá mais rápido sua aprendizagem. Pois a compreensão de um texto escrito depende mais do cognitivo que do domínio da organização gramatical. Ainda de acordo com essas autoras a aquisição da segunda língua só se realiza quando o indivíduo surdo por meio da língua gestual-visual faz relação entre o contexto e o texto, entre a leitura do mundo e a leitura da palavra escrita (Muncinelli, 2013).

O nível de proficiência que o aprendiz possui na sua primeira língua está intensamente ligado ao desenvolvimento na aprendizagem de uma segunda língua.

$\mathrm{Na}$ aquisição e aperfeiçoamento da segunda língua, é fundamental despertar o interesse das crianças para envolver-se no aprendizado, e torná-lo o mais significativo e prazeroso possível. Resgatando conhecimentos prévios, baseando-nos na familiaridade que a pessoa já tem com histórias que lhe serão apresentadas, pode se fixar o vocabulário da segunda língua e apresentar novas estruturas de linguagem (Kyle, 1999).

Essas habilidades de linguagem na segunda língua serão úteis não apenas para conferir-lhes mais confiança em expressar-se nesse idioma, mas também em constituir um maior conhecimento que poderá ser utilizado em situações posteriores em que devam construir frases na língua portuguesa e fortalecer suas capacidades linguísticas e a constituição de um repertório de expressões da nova língua (Kyle 1999, Brasil, 2002).

No caso específico do surdo, o desenvolvimento na aprendizagem da língua portuguesa dependerá do desempenho adquirido em Língua Brasileira de Sinais, pois é por meio desta que será feita primeiramente a leitura do mundo para posteriormente fazer a leitura da palavra em língua portuguesa, promovendo e facilitando o acesso à escrita. Uma das estratégias muito utilizadas no processo de uma segunda língua é da leitura, com o ensino da língua portuguesa para surdo não se faz diferente. Segundo Quadros (1997), a compreensão da leitura pode favorecer o aprendizado de uma língua de forma rápida e eficiente.

O processo da leitura permite decodificar signos, compreender o mundo, fazendo um esforço rigoroso ao cérebro, trabalhando a memória e a emoção. Com o ato de ler, o sujeito além de lidar com a capacidade simbólica da palavra, trabalha também com a habilidade de interação oferecida pela mesma, envolvendo elementos específicos da linguagem e da experiência de vida dos indivíduos, como: signos, frases, sentenças, argumentos, provas formais e informais, objetivos, intenções, ações e motivações.

Segundo Kleiman (2004), a leitura é uma atividade complexa devido aos múltiplos processos cognitivos utilizados pelo leitor ao construir o sentido de um texto, já que ela "não se dá linearmente, de maneira cumulativa, em que a soma do significado das palavras constituiria o significado do texto."

Sabe-se que o indivíduo em algum momento utiliza seus estímulos sonoros para pautar a sua produção escrita, relacionando o que é escrito ao que é falado e, mediante esta compreensão, torna-se possível à construção de hipóteses que lhe permitem prever, antecipar e corrigir seus erros. Porém, a criança surda, mesmo que exposta a estímulos sonoros possui uma incompatibilidade com esses estímulos devido a sua privação sensorial auditiva, tornando-se indispensável à apresentação da língua portuguesa na modalidade escrita, para a acessibilidade visual do surdo. Nesse sentido não se pode impor ao surdo a aprendizagem da língua portuguesa na sua modalidade oral. Sua aquisição deve se pautar em leitura e escrita. Para escrever, como foi dito antes, o indivíduo deve ter como base a leitura que vai desde a de um livro até outras diversidades, como leitura de mundo que envolve outros conhecimentos, chamados prévios (Klieman, 2000, 2004). 
Sabendo disso não é recomendável que se cobre da pessoa com surdez uma produção escrita na língua portuguesa da mesma forma que se exige a produção de uma pessoa ouvinte.

Para os surdos, a aprendizagem da escrita da língua portuguesa torna-se ainda mais complexa em razão de fatores, como: a aquisição tardia da língua de sinais pelos surdos - o que resulta, muitas vezes, em atrasos linguístico-cognitivos - e as práticas pedagógicas pautadas no aspecto fônico da língua portuguesa. Como já se observou anteriormente a escola tende a praticar um ensino da língua portuguesa baseada no oral tendo em vista que desta forma o ouvinte consegue assimilar mais facilmente o aprendizado dessa língua. Segundo Silva (2001, p. 43-44):

É necessário enfatizar que as condições de aprendizagem da leitura e da escrita no processo de escolarização do aluno surdo dependem, por via de regra, do modo pelo qual são encaradas suas dificuldades e as diferenças ocorridas no processo educacional pelas instituições, levando-o a adquirir confiabilidade nas dificuldades encontradas. Nessa mesma ótica é preciso destacar que o surdo, antes de ter dificuldades na escola, apresenta dificuldades de aquisição da língua, instalando-se a grande diferença de escolarização entre o surdo e o ouvinte.

Como as metodologias de ensino/aprendizagem da escrita, no Brasil, são baseadas, na maioria dos casos, no aspecto fonológico da língua e as palavras, por vezes, são apresentadas de forma descontextualizadas e mecânicas, sem ênfase no significado, o desempenho do Surdo em língua portuguesa escrita, que poderia ser muito bom, acaba sendo ineficaz e insuficiente (Koch, 1997).

O ensino da língua portuguesa para a pessoa com surdez de ser baseada na concepção bilíngue sendo que a segunda língua deve ser ofertada, como já foi exposto, na modalidade escrita e, como base para intermediar esse aprendizado deve se considerar a língua materna dessa pessoa. Com isso observa se a necessidade de que não só o aluno domine sua língua como também aquele que o instruirá na segunda língua.

Na modalidade escrita da língua portuguesa há que se observar algumas diferenças de produção do aluno com surdez da de um ouvinte também em relação à estrutura das orações. Em textos produzidos por pessoa com surdez é comum se perceber diferenças em relação ás produções de ouvintes, tais como: dificuldades com o léxico, desconhecimento dos processos de formação de palavras, não contração de preposição com o artigo; o uso dos verbos geralmente no infinitivo sem as suas conjugações em tempos e modos, uso "inapropriado" das preposições, ausência de conectivos em geral e de verbos de ligação nas sentenças, colocação indevida do advérbio na frase, falta de domínio, uso limitado de outras estruturas de subordinação dentre outros (Koch, 1997).

Avaliando as considerações expostas acima completa-se que aquisição da língua portuguesa escrita demanda atividades de reflexão voltadas para a observação e a análise de seu uso, para o conhecimento de sua estrutura e sistema linguístico, funcionamento e variações em contextos de prática, tanto nos processos de leitura como na produção de texto. A reflexão sobre a língua permite ao aluno conhecer e usar a gramática normativa, produzir os vários gêneros textuais e ampliar sua competência e desempenho linguístico e o aluno com surdez quando inserido num contexto biligue que permita associações visuais em que se possibilite uma contextualização para atribuição de sentidos às diversas situações didáticas que lhe serão apresentadas consegue assimilar e utilizar a língua portuguesa como língua de instrução.

\section{Conclusão}

A educação das pessoas com surdez tem passado por várias mudanças desde os tempos antigos iniciando com o oralismo que não resultou em um desenvolvimento pleno do Surdo devido a esse tipo de educação não contemplá-lo em suas necessidades, em seguida a comunicação total que também deflagrou apesar de considerar o surdo de forma mais abrangente não conseguiu tirá-los da segregação quando expostos a situações cotidianas não estavam preparados para enfrentá-las. 
Posteriormente com a abordagem do bilinguismo esta se mostrou a mais adequada, pois trás a possibilidade de inserção do surdo de forma mais eficaz na diversidade de situações a que uma pessoa esteja exposta ao fazer parte de uma sociedade.

Percebe-se que a educação do Surdo foi marcada pela proibição nas escolas da utilização da sua língua natural, a língua de sinais. Alunos e professores foram proibidos de utilizá-la. A proibição da comunicação gesto visual, na escola, se transpôs para o ambiente familiar e social. Atualmente é um paradigma que precisa ser quebrado para que haja a inclusão total do surdo. Para tanto, “o bilinguismo é o método educacional, mais usado e adequado” (Quadros, 1997)

De acordo com essa autora é preciso também se considerar outros aspectos para que se possa ter êxito na educação do surdo. "Deve-se atentar, também, para a cultura na qual a criança está inserida, uma vez que a comunidade surda apresenta uma cultura própria que deve ser respeitada e cultivada". (Quadros, 1997, p. 28)

Percebeu-se então que o Surdo como o ouvinte tem a capacidade de desenvolver-se a partir da comunicação com seu semelhante. A língua de sinais apresenta-se como porta de entrada para a possibilidade de aquisição da segunda língua, principalmente na sua modalidade escrita, permitindo que o indivíduo com surdez insira-se na comunidade como participante ativo de seu desenvolvimento. Nesse sentido a língua portuguesa deve ser ofertada ao Surdo nessa modalidade e também devese considerar a sua organização e estruturas frasais são apresentadas de forma diferente por estes usuários.

\section{Referências}

Araújo, B. C. de, Quixabeira, A. P., Padilhas, O. P., \& Ferreira, R. K. A. (2020). Adapted sport: Perception and methodologies of Physical Education teachers in public schools. Research, Society and Development, 9(7), e792974707. https://doi.org/10.33448/rsd-v9i7.4707

Damázio, M. F. M. (2007). Deficiência Auditiva. MEC/SEESP.

Kajima, C. K. \& Segala, S. R. (2008). Língua Brasileira de Sinais: A imagem do Pensamento. Editora Escala

Kleiman, A. (2000). Oficina de leitura: teoria e prática. (7a ed.), Pontes.

Kleiman, A. B. (2004). Abordagens da leitura. Scripta, 8(14), 13-22. Recuperado de http://periodicos.pucminas.br/index.php/scripta/article/view/12538

Koch, I. V.(1997). O texto e a construção dos sentidos. Contexto.

Kyle, J. O. (1999). Ambiente bilíngue: alguns comentários sobre o desenvolvimento do bilinguismo para surdos. In: Skliar, C. (Org.). Atualidades da educação bilíngue para surdos. (p.15-26). Mediação

Machado, P. C. (2007). A influência da linguagem viso-espacial no desenvolvimento cognitivo da criança surda. http://www.periodicos.udesc.br/index.php/linhas/article/viewFile/1286/1097.

Muncinelli, S. E. (2013). Libras: Língua Brasileira de Sinais. Revista Extensão em Foco, Caçador, 1(1), 27-33.

Nader, J. M. V. \& Pinto, R. C. N. (2011). Aquisição tardia de linguagem e desenvolvimento cognitivo do surdo. Estudos Linguísticos, 40(2), $929-943$.

Nóbrega, J. D. et al., (2012). Identidade surda e intervenções em saúde na perspectiva de uma comunidade usuária de língua de sinais. Revista Ciência \& Saúde Coletiva, 17 (3), 671-679

Quadros, R. M., \& Perlin, G. (orgs) (2007). Estudos Surdos II (Série Pesquisas). Arara Azul.

Quadros, R. M. de. (1997). Aquisição da linguagem por crianças surdas. In: Giuseppe Rinaldi. (Org.). Educação Especial: Língua Brasileira de Sinais. MEC, 63-80.

Sacks, O. (1990). Vendo Vozes: uma jornada pelo mundo dos surdos. Imago.

Santana, A. P. (2007). Surdez e linguagem: aspectos e implicações neurolinguísticas. Plexus.

Skliar, C. (2006). Educação e Exclusão: abordagens socioantropológicas em Educação Especial. Mediação

Schemberg, S., Guarinello, A. C., \& Massi, G. (2012). O ponto de vista de pais e professores a respeito das interações linguísticas de crianças surdas. Revista Brasileira de Educação Especial, 18(1), 17-32.

Strobel, K. L. (2008). Surdos: os vestígios culturais não registrados na história [tese]. Florianópolis (SC): Universidade Federal de Santa Catarina. 